POLITEKNIK NEGERI NUSA UTARA

\title{
EVALUASI PELAKSANAAN PROGRAM PENCEGAHAN PENANGGULANGAN DAN PENATALAKSANAAN PENYAKIT KUSTA DI PESISIR PULAU MAHANGETANG KABUPATEN SANGIHE TAHUN 2019
}

\author{
EVALUATION of THE IMPLEMENTATION of THE PREVENTION PROGRAM FOR THE \\ PREVENTION and MANAGEMENT of LEPROSY ON THE COAST of MAHANGETANG ISLAND \\ SANGIHE REGENCY 2019
}

\author{
Detty Jeane Kalengkongan, Yeanneke Liesbet Tinungki \\ Program Studi Keperawatan Jurusan Kesehatan Politeknik Negeri Nusa Utara \\ Email:kalengkongandetty@gmail.com
}

\begin{abstract}
Abstrak: Penyakit kusta bila tidak ditangani dengan cermat, dapat menyebabkan masalah yang kompleks, baik dari segi medis yaitu cacat fisik, juga sampai pada masalah sosial budaya dan keamanan. Untuk mencapai eliminasi kusta pemerintah melakukan upaya menurunkan beban kusta dan memutuskan transisi kusta melalui pencegahan dengan upaya pemberian kemoprofilaksis Rifampisin dosis tunggal pada setiap orang yang hidup bersama serta berinteraksi dengan pasien kusta. Pulau Mahangetang merupakan salah satu kampung project demonstrasi (pilot) kegiatan pemberian kemoprofilaksis tahun 2019 oleh karena ditemui kasus kusta dengan jumlah 22 orang. Tujuan penelitian mengevaluasi Pelaksanaan Program Pencegahan Penanggulangan dan Penatalaksanaan kusta di pesisir pulau Mahangetang. Metode penelitian deskritif kualitatif dengan pendekatan fenomenologis. Pengumpulan data diperoleh melalui kuesioner, wawancara secara mendalam serta observasi langsung. Teknik pengambilan sampel adalah purposive sampling dengan 10 informan yang ditentukan oleh peneliti sendiri. Hasil penelitian ini menemukan, Kebijakan dan strategi Input evaluasi pelaksanaan pencegahan penanggulangan dan penatalaksanaan penyakit kusta belum berjalan secara optimal. Proses evaluasi program berjalan sesuai perencanaan, walaupun hasilnya belum maksimal. Output evaluasi pelaksanaan program dengan cakupan 215 orang (43,39\%). Kesimpulan Input pelaksanaan belum berjalan secara optimal. Proses dan output pelaksanaan berjalan baik sesuai dengan perencanaan dengan cakupan 43,39\%. Saran dalam melaksanakan program, sebaiknya melakukan advokasi kepada pihak penentu kebijakan, agar dalam pelaksanaan program dapat berjalan baik sehingga penularan kusta dapat ditekan.
\end{abstract}

Kata kunci: Evaluasi, program, pencegahan, penanggulangan, penatalaksanaan kusta

\begin{abstract}
If not handled carefully, leprosy can cause complex problems, both from a medical perspective, namely physical disabilities, as well as socio-cultural and security issues. To achieve the elimination of leprosy, the government has made efforts to reduce the burden of leprosy and decide the transition to leprosy through prevention by administering a single dose of chemoprophylaxis Rifampicin to everyone who lives together and interacts with leprosy patients. Mahangetang Island was one of the villages for the demonstration project (pilot) for the provision of chemoprophylaxis in 2019 because 22 cases of leprosy were found.The purpose of this research is to evaluate the implementation of the Prevention and Management Program of leprosy on the coast of Mahangetang Island. Qualitative descriptive research method with a phenomenological approach. Data collection obtained through questionnaires, in-depth interviews and direct observation. The sampling technique was purposive sampling with 10 informants who were determined by the researchers themselves. The results of this study found that the policies and input strategies for evaluating the implementation of leprosy prevention and management have not been running optimally. The program evaluation process goes according to plan, although the results were not optimal. The output of program implementation evaluation covered 215 people (43.39\%). In conclusion, the implementation input has not run optimally. The implementation process and output went well in accordance with the planning with a coverage of 43.39\%. Suggestions in implementing the program, it was better to carry out advocacy to policy makers, so that program implementation can run well so that the transmission of leprosy can be suppressed.
\end{abstract}

Keywords: Evaluation, program, prevention, control, management of leprosy. 


\section{PENDAHULUAN}

Kusta (Morbus Hansen, lepra) adalah penyakit kronis menular yang disebabkan oleh Microbacterium leprae. Penyakit kusta bila tidak ditangani dengan cermat, dapat menyebabkan masalah yang kompleks, baik dari segi medis yaitu cacat fisik, juga sampai pada masalah sosial, budaya dan keamanan (Widoyono, 2008).

Penyakit kusta sampai saat ini masih merupakan stigma di masyarakat, keluarga dan tenaga kesehatan. Hal ini desebabkan masih kurangnya pengetahuan atau pengertian, serta kepercayaan yang keliru terhadap kusta (WHO, 2010).

Prevalensi penyakit kusta di Kabupaten Kepulauan Sangihe pada 3 tahun terakhir mengalami peningkatan dari jumlah 23 kasus pada tahun 2017,meningkat menjadi 38 di tahun 2019 (Dinas Kesehatan, 2019). Kasus terbanyak berada di pulau Mahangetang kecamatan Tatoareng dengan jumlah 22 kasus sehingga dikategorikan sebagai kampung high endemis kusta.

Berdasarkan adanya peningkatan kasus kusta, maka pada tahun 2019 pulau Mahangetang Kabupaten Sangihe Propinsi Sulawesi Utara merupakan kampung project demonstrasi (pilot) dengan kegiatan kemoprofilaksis Rifampisin dosis tunggal, sebagai Leprosy Post Exposure Prophylaxis (LPEP), melalui program Kementerian Kesehatan Republik Indonesis dalam penanggulangan kusta melalui pencegahan. (Waworuntu, 2019). Tujuan penelitian mengevaluasi Pelaksanaan Program Pencegahan Penanggulangan dan Penatalaksanaan Penyakit Kusta di pesisir pulau Mahangetang Kabupaten Sangihe Tahun 2019.

\section{METODE PENELITIAN}

Penelitian ini dilaksanakan pada bulan Juli Agustus 2020 di pulau Mahangetang Kabupaten Sangihe. Jenis penelitian yang digunakan deskritif kualitatif dengan pendekatan fenomenologis. Jumlah informan sebanyak 10 orang berdasarkan metode pusposive sampling. Teknik pengumpulan data dilakukan dengan cara wawancara mendalam (deptinterview), kuesioner terstruktur, catatan lapangan serta telaah dokumentasi terhadap input, proses, output. Pengolahan data pada penelitian ini menggunakan analisa data (content analysis).

\section{HASIL PENELITIAN}

Subjek pada penelitian ini sebanyak 10informan yang terdiri dari kepala Dinas Kesehatan Kabupaten Sangihe, kepala Bidang P2PM, pemegang program kusta Dinas Kesehatan, kepala Puskesmas Tatoareng, pemegang program Puskesmas, kepala kampung pulau Mahangetang, tokoh masyarakat/tokoh agama dan 2 responden yang mendapatkan pencegahan kemoprofilaksis.

Karakteristik informan dalam penelitian ini sepertipada tabel sebagai berikut:

Tabel. 1 Karakteristik Informan

\begin{tabular}{cccll}
\hline Inf & Umur & J.K & \multicolumn{1}{c}{ Pekerjaan } & Alamat \\
\hline 1 & 47 & L & Kadis Kes & Tahuna \\
2 & 42 & L & Kabid P2PM & Tahuna \\
3 & 38 & P & ASN & Tahuna \\
4 & 42 & P & Kapus PKM & Kahakitang \\
5 & 38 & P & .ASN & Kahakitang \\
6 & 32 & P & ASN & Mahangetang \\
7 & 52 & L & Nelayan & Mahangetang \\
8 & 46 & L & Pendeta & Mahangetang \\
9 & 41 & P & IRT & Mahangetang \\
10 & 44 & P & IRT & Mahangetang \\
\hline
\end{tabular}

Berdasarkan Tabel 1 Karakteristik umur Informan terbanyak berumur diantara 40-52 tahun, terendah umur 32 tahun, Jenis Kelamin terbanyak perempuan. Pekerjaan terbanyak adalah ASN. Alamat terbanyak berada di Mahangetang.

Input Evaluasi Pelaksanaan Program Pencegahan, Penaggulangan dan Penatalaksanaan Penyakit Kusta

Kebijakan / strategi yang dilakukan oleh Dinas Kesehatan Kabupaten Sangihe pada pelaksanaan program pencegahan, penanggulangan dan penatalaksanaan penyakit kusta yang dilakukan di pesisir pulau Mahangetang dengan pemberian kemoprofilaksis Rifampisin dosis tunggalyaitu dengan melakukan advokasi pada pemerintah daerah, menggalang koordinasilintas sektor, serta melibatkan 
masyarakat melalui sosialisasi dan penyuluhan. Hal ini sesuai pernyataan dari informan sebagai berikut:

"Sebelum pelaksanaan program, kami
melapor kepada bapak Bupati agar
mendapatkan dukungan, sehingga
pelaksanaannya bisa berjalan dengan
baik"(Informan1,2)
"Untuk persiapan pelaksanaan program
ini, kami melakukan koordinasi
dengan pemerintah
(Informan 4,5)
"Pada pelaksanatan"
kami melibatkan pemerintah kampung, tokoh
masyarakat/agama" (Informan 4,5 6)

Selain dalam menjalankan kebijakan/ strategi sumber daya manusia kesehatan (SDM) dapat mempengaruhi keberhasilan suatu kebijakan. SDM pemegang program kusta di puskesmas Tatoareng 1 orang perawat dengan latar belakang pendidikan D3 Keperawatan sudah pernah mengikuti pelatihan kusta kurang lebih 3 tahun yang lalu, namun sampai saat ini belum adanya penyegaran/pelatihan kembali tentang kusta. Disisi yang lain masih merangkap dengan program lain, sehingga dalam pelaksanaan program tidak maksimal. Pada pelaksanaan program, dibantu oleh petugas yang ada di puskesmas pembantu Mahangetang. Bahan sarana dan prasarana untuk menunjang program kusta ditemui bahwa fasilitas belum memadai, belum tersedianya laboratorium khusus, belum adanya busen dan rak pewarna, belum adanya alat bantu protesa/kaki palsu, sandal/sepatu khusus untuk penderita kusta yang kakinya mati rasa. Begitu juga untuk alokasi dana serta anggaran yang masih sangat minim.

$$
\text { Pada pelaksanaan program pemberian }
$$
kemoprofilaksis tahun 2019 di pulau Mahangetang, merupakan program Dinas Kesehatan Provinsi Sulawesi Utara, sehingga alokasi anggaran/dana melalui Dinas Kesehatan Provinsi. Dipilihnya pulau Mahangetang sebagai salah satu project demonstrasi (pilot) karena wilayah kecamatan Tatoareng khususnya pulau Mahangetang merupakan kampung dengan peningkatan kasus kusta terbanyak yaitu 22 orang. Semua informasi ini sesuai pernyataan yang disampaikan oleh informan pada saat wawancara secara mendalam sebagai berikut:

"Petugas pemegang program kustamerangkap
dengan tugas lain, oleh karena keadaan
tenaga yang kurang, namun dibantu oleh
petugas pustu $\quad$ pulau
Mahangetang"(Informan2,4)

"Anggaran/dana pemberian pada program untuk pencegahan tahun 2019, adalah anggaran yang dialokasikan melalui Dinas Kesehatan Provinsi, dan untuk Kabupaten terbatas pada pengobatan pasien yang positif kusta, termasuk biaya operasional pelaksanaan monev, melalui dana alokasi umum (DAU)” (Informan 1,2,3)

"Untuk program pencegahan denganpemberian kemoprofilaksis di tingkat Kabupaten, kami sudah menganggarkandi tahun 2020, namun karena adanya pergserananggaran, maka dana tersebutdipakai untukpenanganan pandemic Covid-19" (Informan 2)

Proses Evaluasi Pelaksanaan Program Pencegahan, Penaggulangan dan Penatalaksanaan Penyakit Kusta

Kegiatan pelaksanaan program dilakukan sesuai dengan perencanaan yang telah disusun. Petugas pemegang program puskesmas bersama bidan desa yang ada di pulau Mahangetang melakukan pendataan dengan mengisi angket panduan kemudian data diolah dalam bentuk laporan lalu dikirim ke Dinas Kesehatan Kabupaten, walaupun ditemui untuk format/angket khusus pendataan kusta yang masih terbatas. Hal ini sesuai pernyataan yang disampaikan oleh informan sebagai berikut:

"Pada pelaksanaan program kemoprofilaksis, terlebih dahulu melakukan pendataan kelompok orang yang dalam pengobatan kusta, serta kelompok masyarakat yang memiliki risiko penularan kusta. Hal ini dilakukan dengan mengisi angket panduan kusta" (Informan 3,5,6)

Implementasi program di pulau Mahangetang dilaksanakan pada bulan April 2019selama 3 hari, dengan sasaran semua masyarakat yang kontak dengan penderita kusta. Sebelum pemeriksaan kesehatan, didahului dengan pemberian sosialisai/penyuluhan yang melibatkan pemerintah kampung, tokoh masyarakat/agama yang bertempat di balai desa pulau 
Mahangetang. Dari total jumlah penduduk sebanyak 685 jiwa, yang diperiksa sebanyak 485 orang dan mendapat kemoprofilaksis Rifampicin dosis tunggal sebanyak 415 orang. Pada pelaksanaan monitoring dan evaluasi setelah pelaksanaan program dilaksanakan bersamaan dengan kegiatan posyandu sebulan sekali, dengan melibatkan kader posyandu di pulau Mahangetang.Pernyataan ini sesuai hasil wawancara secara mendalam dengan informan sebagai berikut:

"sebelum pelaksanaan kegiatan program
pemberian Rifampicin, didahului dengan
sosialisasi/ penyuluhan" (Informan 4,5,6)
"Pada saat pelaksanaan program jumlah yang
diperiksa sebanyak 485orang, yang
mendapatkan Rebagai
pencegahan sebanyak 415 orang, ditemui
positif berdasarkan hasil pemeriksaan
sebanyak 16 orang terdiri dari tipe PB 6
orang dan tipe MB 10 Orang (Informan 2,3 )
"Selain monev yang dilksanakan pada kegiatan
posyandu, petugas pustu juga melakukan
monev secara door to door untuk memantau
keluhan yang timbul setelah pemberian
Rifampicin" (Informan 4,5,6)

Output Evaluasi Pelaksanaan Program Pencegahan Penanggulangan dan Penatalaksanaan Penyakit Kusta

Pelaksanaan evaluasi program pencegahan penanggulangan dan penatalaksanaan dengan pemberian kemoprofilaksis Rifampicin di pulau Mahangetang, mencakup seluruh masyarakat yang dilayani pada tahun 2019 dengan jumlah 415 orang. Dari jumlah 415 orang yang menerima pemberian Rifampicin terdapat 205 orang yang berhasil dievaluasi pada pelaksanaan bulan September 2020 oleh tim Dinas kesehatan Provinsi Sulawesi Utara bersama Dinas Kesehatan Kabupaten serta Puskesmas Tatoareng.Diantara yang diperiksa ditemui sebanyak 16 orang positif kusta terdiri dari 10 orang kusta tipe PB dan 6 orang kusta tipe MB. Keberhasilan suatu program dilihat dari cakupan sebanyak $100 \%$. Namun pada pelaksanaan kegiatan ini cakupan hanya mencapai $49,39 \%$. Semua informasi ini sesuai pernyataan informan sebagai berikut:

\footnotetext{
"Bersama tim dari Dinas Kesehatan Provinsi Sulawesi Utara melakukan evaluasi yang dilaksanakan pada bulan September selama 2
}

hari dengan memeriksa kembali masyarakat yang mendapatkan kemoprofilaksis sebagai pencegahan kusta pada tahun 2019"(Informan2,3)

"Dari jumlah 415 orang yang mendapatkan kemoprofilaksis pada tahun 2019, hanya 205 orang yang berhasil dievaluasi, oleh karena sebagian besar masyarakat berada diluar kampung ”(Informan 2)

\section{PEMBAHASAN}

Dari hasil penelitian ini dapat digambarkan bahwa dalam pelaksanaan program pencegahan penanggulangan dan penatalaksanaan penyakit kusta melalui input, proses dan output belum berjalan sebagaimana mustinya. Semua hal tersebut secara rinci dibahas sebagai berikut:

Input evaluasi pelaksanaan program pencegahan, penaggulangan dan penatalaksanaan kusta

Kebijakan/strategi pelaksanaan program pencegahan penanggulangan dan penatalaksanaan penyakit kusta sebagai project demonstrasi oleh Dinas Kesehatan Provinsi bersama Dinas Kesehatan Kabupaten di pulau Mahangetang belum berjalan secara optimal, hal ini peneliti dapatkan melalui wawancara mendalam dengan informan pemegang program Dinas Kesehartan bahwa dari hasil evaluasi yang dilakukan yaitu dari 415 orang yang diperiksa dan mendapatkan kemoprofilaksis/pencegahan pada tahun 2019, yang berhasil dievaluasi pada bulan September 2020 hanya sebanyak 205 orang, hal ini disebabkan sebagian masyarakat bekerja sebagai nelayan dan yang lain tidak berada di tempat. Hal ini terlihat bahwa belum adanya sinergi dan keterpaduan dalam program. Penelitian ini sama dengan penelitian yang dilakukan oleh (Maranatha, 2012) dengan tidak berhasilnya program evaluasi pengendalian penyakit kusta yaitu dari target $100 \%$ yang dicapai hanya $25 \%$.

Menurut pandangan Edwards III, 1980 (dalam Subarsono,2010) mengatakan bahwa keberhasilan pelaksanaan kebijakan akan ditentukan oleh komunikasi implementasi, dimanaterdapat tujuan dan sasaran kebijakan yang harus disampaikan kepada kelompok 
sasaran. Komunikasi memegang peranan penting bagi berlangsungnya koordinasi implementasi kebijakan.

Permasalahan kusta tidak dapat diselesaikan oleh sektor kesehatan saja dan membutuhkan waktu yang cukup panjang dalam penyelesaiannya. Oleh karena itu dibutuhkan komitmen dari pemangku kepentingan melalui penguatan advokasi serta koordinasi dan kerja sama lintas program dan lintas sektor dalam penanggulangan kusta (Kemenkes, 2019).

Selain dalam menjalankan kebijakan program pencegahan penanggulangan dan penatalaksaan kusta, alokasi SDM kesehatan, juga dapat mempengaruhi keberhasilan suatu kebijakan. Saat penelitian dilakukan, peneliti menemui bahwa petugas pemegang program kusta masih merangkap dengan program yang lain, sehingga dalam menjalankan tugasnya tidak maksimal. Hal ini belum sejalan dengan target dan strategi pemerintah untuk pencapaian eliminasi kusta, dimana dengan ketersediaan SDM kesehatan dalam mendukung keberhasilan suatu program. SDM dalam penanggulangan kusta merupakan tenaga kesehatan yang memiliki keahlian dan kompetensi sesuai ketentuan peraturan perundang-undangan, termasuk pengelola program baik tingkat pusat, provinsi, kabupaten/kota dan puskesmas (Kemenkes 2019).

Penelitianini sama dengan penelitian yang dilakukan oleh (Muh Zul Azhri Rustam, 2018), dengan hasil penelitian ditemukan bahwa peran petugas kesehatan berpengaruh terhadap kepatuhan minum obat MDT kusta.

Petugas kesehatan memiliki peran penting dalam melayani masyarakat. dengan pelayanan yang prima maka masyarakat akan merasa nyaman dan mau terlibat dalam program-program yang dilakukan. Namun disisi lain kegiatan program yang dilakukan di pulau Mahangetang tidak hanya tanggung jawab Dinas Kesehatan dan Puskesmas, melainkan kerjasama dengan pihak lain yang diperlukan untuk menunjang keberhasilan penanggulangan kasus kusta. Pelatihan SDM perlu dianggarkan, agar dalam menjalankan program sesuai dengan prosedur. Hasil yang ditemui pemegang program kusta sudah pernah mengikuti pelatihan kurang lebih 3 tahun yang lalu, namun sampai saat ini belum diikut sertakan untuk penyegaran kembali. Dan untuk petugas pembantu program di kampung, belum pernah mengikuti pelatihan. Penelitian ini sejalan dengan penelitian yang dilakukan oleh(Abd, Rahman, dkk. 2016), menyatakan SDM petugas kusta seharusnya diikut sertakan lagi untuk pelatihan, agar memahami betul serta bertanggung jawab penuh dalam mewujudkan target eliminasi kusta.Begitu juga denganbahan, sarana dan prasaran untuk program kusta semuanya belum tersedia di puskesmas Tatoareng. Hal ini peneliti temui saat melakukan pemantauan langsung di tempat penelitian. Menurut (Subarsono., A.G, 2012) berpendapat bahwa ketersediaan peralatan merupakan sarana penunjang yang digunakan untuk operasional implememtasi suatu kebijakan. Terbatasnya fasilitas peralatan yang diperlukan dalam pelaksanaan kebijakan menyebabkan gagalnya pelaksanaan program. Untuk mengatasi tersedianya sarana dan prasarana, dinas terkait perlu memperkuat perencanaan dalam pengadaan untuk kebutuhan program kasus kusta. Disisi lain dinas terkait segera mengupayakan perencanaan pengadaan obat untuk pencegahan terjadinya kusta. Penelitian yang dilakukan oleh (Kiki, A.F, 2016), terdapat hubungan antara ketersediaan obat dengan kesembuhan pasien kusta.Penelitian ini didukung oleh (Pangaribuan, J., F 2012) mengungkapkan bahwa dalam penanganan kusta di RS Kusta Hutasalem fasilitasnya lengkap, termasuk ketersediaan obat.Dana serta anggaran untuk program pencegahan penyakit kusta dengan pemberian Rifampicin dosis tunggal di pulau Mahangetang adalah alokasi dana dari Dinas Kesehatan Provinsi di tahun 2019. Menurut peneliti seharusnya Dinas Kesehatan Kabupaten secara rutin sudah mengalokasikan anggaran untuk penanganan kusta, demi menekan angka penyebarannya. Ditemui bahwa bahwa Dinas Kesehatan baru menganggarkan pada tahun 2020 untuk program pencegahan, serta penanggulangan kusta, namun hal ini tidak terealisasi oleh karena anggaran dialihkan dalam penanganan pandemik Covid-19. Penelitian ini didukung dengan penelitian yang dilakukan oleh (Abd, Rahman, dkk. 2014), mengatakan bahwa alokasi dana 
untuk program kusta dianggarkan melalui Bantuan Operasional Kesehatan (BOK), namun tidak memadai. Bantuan Operasional Kesehatan (BOK) dan Dana Alokasi Umum (DAU) merupakan bantuan pemerintah yang bersumber dari anggaran pendapatan dan belanja Negara, anggaran dan pendapatan belanja daerah atau sumber lain sesuai ketentuan peraturan perundangundangan dalam menyelenggarakan pelayanan kesehatan yang diutamakan untuk promotif dan preventif pada dinas Kesehatan Provinsi, Kabupaten/Kota, Puskesmas dan jaringannya termasuk Posyandu (Kemenkes, 2019).

Hal ini menggambarkan bahwa dukungan Pemerintah Daerah dalam menyediadakan alokasi anggaran pada program pencegahan penanggulangan serta penatalaksanaan kasus kusta belum memadai. Sudah seharusnya hal ini mendapatkan perhatian khusus pemerintah daerah dalam menunjang program pemerintah pusat untuk menekan penyebaran kusta, oleh karenapulau Mahangetang merupakan salah satu ikon objek wisata yang dipromosikan karena adanya gunung api bawah laut.

\section{Proses evaluasi pelaksanaan program penanggulangan, pencegahan dan penatalaksanaan kusta}

Pelaksanaan program sesuai dengan perencanaan antara dinas Kesehatan Provinsi dan dinas Kesehatan Kabupaten yaitu dilaksanakan pada bulan April tahun 2019. Sebelum pelaksanaan kegiatan ini diberikan sosialisasi/penyuluhan. Pada kegiatan tersebut berhasil diperiksa sebanyak 485 orang dari jumlah penduduk sebanyak 685 orang, dan diberikan kemoprofilaksis Rifampicin sebagai pencegahan sebanyak 415 orang diluar ibu hamil, anak dibawah 2 tahun dan masalah lain Dalam pelaksanaan program seharusnya mencakup jumlah keseluruhan penduduk yang ada. Hal ini tidak sejalan dengan program (Kementerian Kesehatan RI, 2019), dimana dalam pencegahan dan penanggulangan kusta untuk menekan penularannya secara meluas.Temuan peneliti menggambarkan bahwa belum terkoordinasinya antara pemegang program dan petugas pustu, sehingga pelaksanaan program tidak maksimal. Penelitian ini didukung oleh (Mulyadi, A, 2017), mengatakan bahwa belum terkoordinasinya antara pemegang program puskesmas dan petugas yang ada di pustu sehingga terhambatnya pelaksanaan program.

Output evaluasi pelaksanaan program Pencegahan Penanggulangan dan Penatalaksanaan Penyakit Kusta

Tingkat keberhasilan suatu program diukur apabila cakupannya mencapai $100 \%$. Berdasarkan hasil penelitian, ditemui bahwa keberhasilan pelaksanaan program di pulau Mahangetang setelah dilakukan evaluasi pada bulan September 2020 oleh tim Dinas Kesehatan Provinsi bersama-sama dengan tim Dinas Kesehatana Kabupaten sebanyak 215 orang (49,39\%. Hal ini menggambarkan bahwa penatalaksaan program belum maksimal. belum terkoordinasinya dengan baik dalam perencanaannya. Hal ini tergambar saat pelaksanaan kegiatan program tidak dihadiri oleh pemangku kepentingan yang ada di kecamatan. Menurut Kemenkes 2019, bahwa dalam penanggulangan kusta memperoleh komitmen pemerintah baik ditingkat Kabupaten maupun tingkat Kecamatan, adanya penguatan peran serta masyarakat dan organisasi kemasyarakatan yang mempunyai peran penting agar eliminasi kusta bisa ditekan dan tercapai.

Hasil penelitian yang diperoleh peneliti saat melakukan kunjungan rumah pada responden yang mendapatkan kemoprofilaksis, menggambarkan bahwa mereka sangat mendukung kegiatan program yang dilakukan. Penelitian ini didukung oleh (Bujawati,E., Nildawati \& Asni Syamsu Alam, 2015), dengan hasil penelitian $(83,5 \%)$, sebagian besar pasien kusta memiliki persepsi yang positiftentang penyakit kusta. Lebih lanjut dalam penelitian yang dilakukan oleh (Rustam Muh Azhri, 2018), ditemui bahwa peran petugas kesehatan ada pengaruh terhadap kepatuhan minum obat MDT. Keberhasilan penanganan kasus kusta dapat dilakukan dengan kegiatan sosialisasi/penyuluhan, pendidikan/promosi kesehatan. Karena promosi kesehatan akan memiliki efek/output yang baik apabila dalam prosesnya menggunakan 
metode maupun media yang baik. Promosi kesehatan pada dasarnya merupakan proses komunikasi dan proses perubahan prilaku (Notoatmodjo, 2010).

Hasil penelitian ditemukan saat wawancara langsung dengan informan petugas pustu, menuturkan untuk penyuluhan sering disampaikan saat melakukan kunjungan rumah, namun belum maksimal, oleh karena sampai saat ini pengetahuan tentang kusta masih sangat kurang, karena belum pernah mengikuti pelatihan. Demikian juga tidak ditunjang dengan alat peraga yang tersedia. Hal ini didukung oleh penelitian yang dilakukan oleh (Muhamad S, 2015),Dengan hasil menggunakan metode ceramah lebih efektif dalam meningkatkan pengetahuan siswa tentang kusta daripada metode leaflet.

\section{KESIMPULAN}

Berdasarkan hasil penelitian dan pembahasan maka dapat disimpulkan bahwa:

Kebijakan/strategi Input Evaluasi pelaksanaan program pencegahan, penanggulangan dan penatalaksanaan penyakit kusta di pesisir pulau Mahangetang belum berjalan secara optimal. Proses evaluasi pelaksanaan program dilakukan sesuai perencanaan, walaupun hasilnya belum maksimal.Output Evaluasi pelaksanaan program dengan cakupan sebanyak 215 orang $(49,39 \%)$ pada tahun 2020. Saran Melalui penelitian ini, peneliti merekomendasikan Agar Dinas Kesehatan dan Puskesmas terkait dalam pelaksanaan program sebaiknya dapat melakukan advokasi kepada pihak penentu kebijakan dalam hal ini pemerintah daerah dan pemerintah kecamatan agar dalam pelaksanaan program dapat berjalan dengan baik. Penambahan dan pemetaan SDM serta adanya pelatihan yang berkesinambungan bagi petugas pemegang program kusta.

\section{DAFTAR RUJUKAN}

Bujawati,E., Nildawati \& Asni Syamsu Alam, 2016. Gambaran Persepsi Pasien tentang Penyakit Kusta dan Dukungan Keluarga pada Pasien Kusta di RS Dr. Tajudin Chalid Makasar Tahun 2015. Jurnal ilmiah (Online). www.google.com. Diakses tanggal 1 Oktober 2020 Jam 1045
Dinas Kesehatan, Kabupaten Kepulauan Sangihe 2020. Profil Dinas Kesehatan Tahun 2018

Edwards III, 1980 (dalam Subarsono, 2010), Analisi Kebijakan Publik. Konsep Teori dan Aplikasi. Yogyakarta: Pustaka Pelajar

Kemenkes R.I, 2011. Keputusan Menteri Kesehatan RI. Tentang Pedoman Penyusunan Perencanaan Sumber Daya Manusia Kesehatan di Tingkat Propinsi, Kabupaten dan Rumah Sakit.

Kemenkes R.I 2019. Peraturan Menteri Kesehatan Republik Indonesia Nomor 11 tahun 2019. Tentang Penanggulangan Kusta. https://www.kemenkes.go.id. Diakses Tanggal 27 Februari 2020.

Kiki Agustin, Fatmala, 2016. Analisis Faktor yang Berhubungan dengan KepatuhanMinum Obat Kusta di Kecamatan Pragaan. Http://ejournal.unair.ac.id. Diakses tanggal 29 September 2020 Jam 11.20

Maranatha, L.A, 2015. Evaluasi Program Pengendalian Penyakit Kusta di UPTD Puskesmas Cikampek Kabupaten Karawang Periode Januari sampai dengan Desember 2012. Jurnal Ilmiah (Online). www.google.com. Diakses tanggal 29 September 2020 Jam 11.45

Muhamad, S, 2015. Efektifitas Promosi Kesehatan tentang Kusta dengan Metode Ceramah dibandingkan dengan Leaflet bagi SMA I Teluk Batang Kayong Utara. Jurnal ilmiah (online). www.neliti.com. Diakses tanggal 1 Oktober 2020 Jam 10.15

Mulyadi, A, 2017. Upaya Penderita Kusta Dalam Mencegah Derajat Kecacatan. http:www.google.com.Diakses tanggal 29 September 2020 Jam 10.30

Notoatmodjo, S, 2010. Ilmu Prilaku Kesehatan. Rineka Cipta, Jakarta

Pangaribuan, J., F, 2012. Pengaruh Faktor Presdisposisi Pendukung dan Pendorong terhadap Pencegahan Kecacatan Pasien Penyakit Kusta di RS Kusta HutasalemKabupaten Tobasa tahun 2012. Jurnal.usu.ac.id.www.google.com. Diakses tanggal 1 Oktober 2020 Jam 21.30

Rahman, Abd., Hasanah., \& Nur Suci Dwi Wulan, 2016. Evaluasi Program Pengendalian Penyakit Kusta di Wilayah Kerja Puskesmas Lompentodea Kecamatan Parigi Barat Kabupaten Parigi. Jurnal (Online), Volume 7 No 2 Oktober 2016, http:www.google.com.Diakses tanggal 29 September 2020 Jam 10.30 
Rustam Muh Azhri, 2018. Determinan Keberasilan Pengobatan Multi Drug Therapy pada Penderita Kusta Tipe Multibaciler. Http://jurnal. stikesyrsds.ac.id. Diakses tanggal 1 Oktober 2020 Jam 11.00

Subarsono, A.G, 2012. Analisis Kebijakan Publik. Yogyakarta: Pustaka Pelajar

Sugyono, 2009. Metode Penelitian Kuantitatif, Kualitatif. R dan D. Bandung

Waworuntu, 2019. Kemoprofilaksis Sebagai Leprosy Post Exposure Prophylaxis Mampu Turunkan
Kasus Baru Kusta. P2P. Kemenkes RI, Direktorat Jenderal Pencegahan Pengendalian Penyakit. Diakses tanggal 28 Maret 2020

Widoyono, 2008. Penyakit. Tropis.Penerbit Erlangga: Jakarta

Word Health Organisation, 2010. InfoDatin. Pusat Data dan Informasi Kementerian Kesehatan Republik Indonesia

Yin, 2011. Metodelogy Buku Cetak Ulang Rajawali: Pers 